\title{
Screening Palliative Patients with the \\ Distress Thermometer: A Feasibility Study
}

\author{
B. Middleton, ${ }^{1}$ J. Lee, ${ }^{1}$ D. Horrex,${ }^{1}$ D. Mittal, ${ }^{1}$ G. Aggarwal ${ }^{1}$
}

${ }^{1}$ Concord Centre for Palliative Care, Concord Repatriation General Hospital, Concord, NSW, Australia

\section{INTRODUCTION}

The early identification and assessment of distress in patients facing life-threatening illnesses is crucial for its management, but distress remains poorly recognised by clinicians ${ }^{1}$. One of the most efficient distress screening tools is the Distress Thermometer, a patient-rated, single-item, 11-point visual analogue scale ${ }^{2,3}$. At the Concord Centre for Palliative Care in Sydney, standard care includes daily screening of symptoms as part of the Palliative Care Outcomes Collaboration, a nationally-funded data collection program. This screening does not include an overall self-rated distress measure. Given that clinicians often overlook distress and because we are not routinely screening for distress, it follows that we may be recognising distress too late and managing it sub-optimally. We designed a brief feasibility study to assess if introducing the Distress Thermometer into clinical practice might help to rectify these problems.

\section{OBJECTIVES}

To determine the feasibility and acceptability of implementing the Distress Thermometer in addition to standard care in an inpatient palliative care unit.

\section{METHODS}

We administered the Distress Thermometer to 30 consecutive consenting patients admitted to the Concord Centre for Palliative Care, within two days of their admission, in June 2017. Patients deemed incapable of understanding or completing the Distress Thermometer were excluded from the study. Interpreters were used for patients of non-English speaking backgrounds. Those patients scoring $\geq 4$ were deemed to have clinically significant distress ${ }^{4}$, and brief inquiries were then made of these patients to ascertain the cause(s) of their distress. The duration of screening was recorded, and patients' acceptability of the screening tool was assessed using a four-point Likert scale. We compared the detection rate of the Distress Thermometer with standard care and reviewed existing referrals to Psychology and Social Work to ascertain if these patients had been appropriately referred for management of distress.

\section{RESULTS}

The average age of respondents was 74.6 years, and $53 \%$ were female. Non-English speakers accounted for $17 \%$ of the patients who partook in the study. Malignancy was present in $77 \%$ of patients, while the remaining $23 \%$ had chronic or degenerative illnesses. The mean time taken to complete the Distress Thermometer was 2.8 minutes (see range in Figure 1). The screen was positive in $76 \%$ of patients. In terms of acceptability, $57 \%$ of patients found the Distress Thermometer easy or very easy to use (see Figure 2)

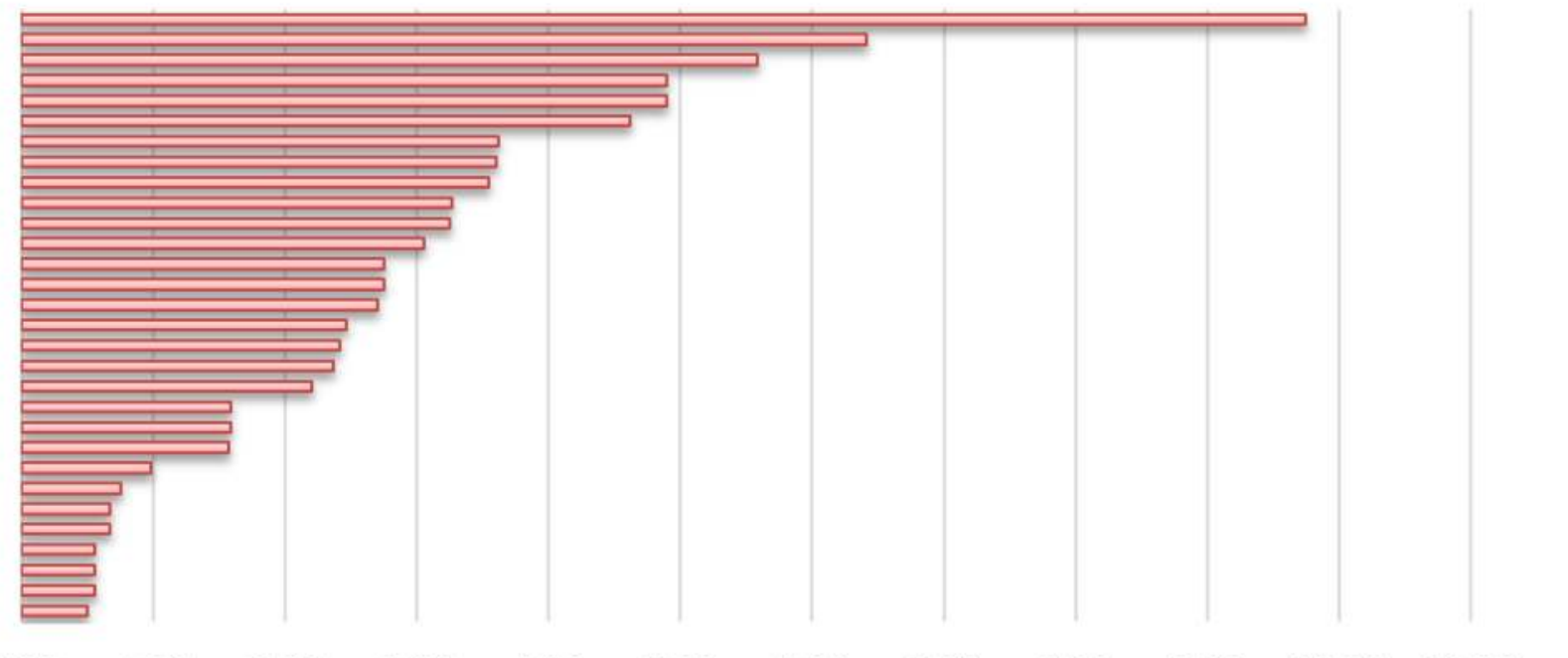

Figure 1. Time taken to complete the Distress Thermometer in descending order for all participants (min:sec)

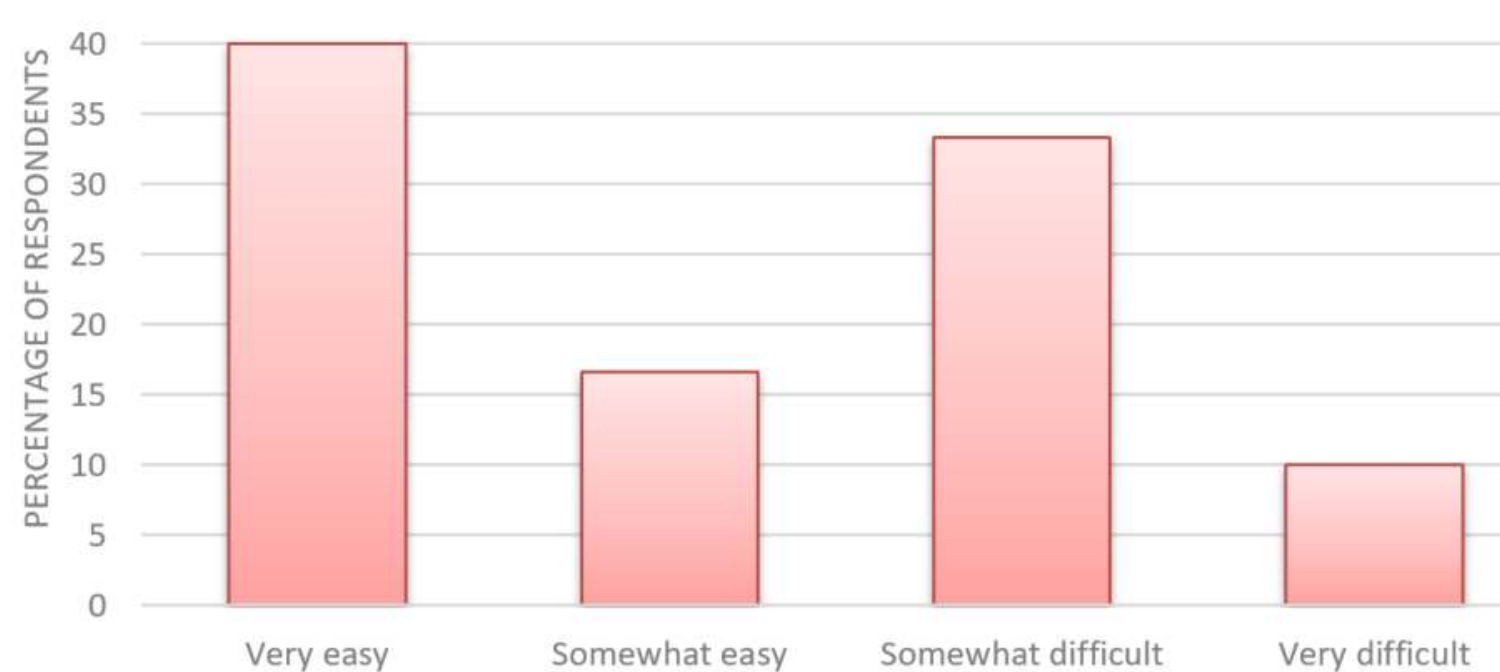

Figure 2. Acceptability of the Distress Thermometer

In $10 \%$ of patients, distress was reported which had not been detected by standard screening, while $20 \%$ of patients had psychological or social distress detected by the Distress Thermometer where standard assessment had not triggered a referral for Psychology or Social Work review.

\section{DISCUSSION AND CONCLUSION}

We demonstrated that use of the Distress Thermometer was both efficient and acceptable to patients in a palliative care inpatient unit. Staff of the unit were aware the study was being undertaken, and may have been more vigilant with identifying distress and ensuring appropriate referrals were made, thus potentially limiting our findings. Questions which need further consideration include how frequently we should be screening our inpatients for distress, and if introduced into clinical practice, whether a score $\geq 4$ on the Distress Thermometer should lead to automatic referral.

Nonetheless, the Distress Thermometer identified additional distress not detected with standard care and provided opportunities to improve management of palliative patients with distress.

\section{ACKNOWLEDGEMENTS}

The authors would like to thank the National Comprehensive Cancer Network for their permission to use the Distress Thermometer $^{2}$. We would also like to thank all participating patients, their families, and staff at the Concord Centre for Palliative Care, for taking part in this research.

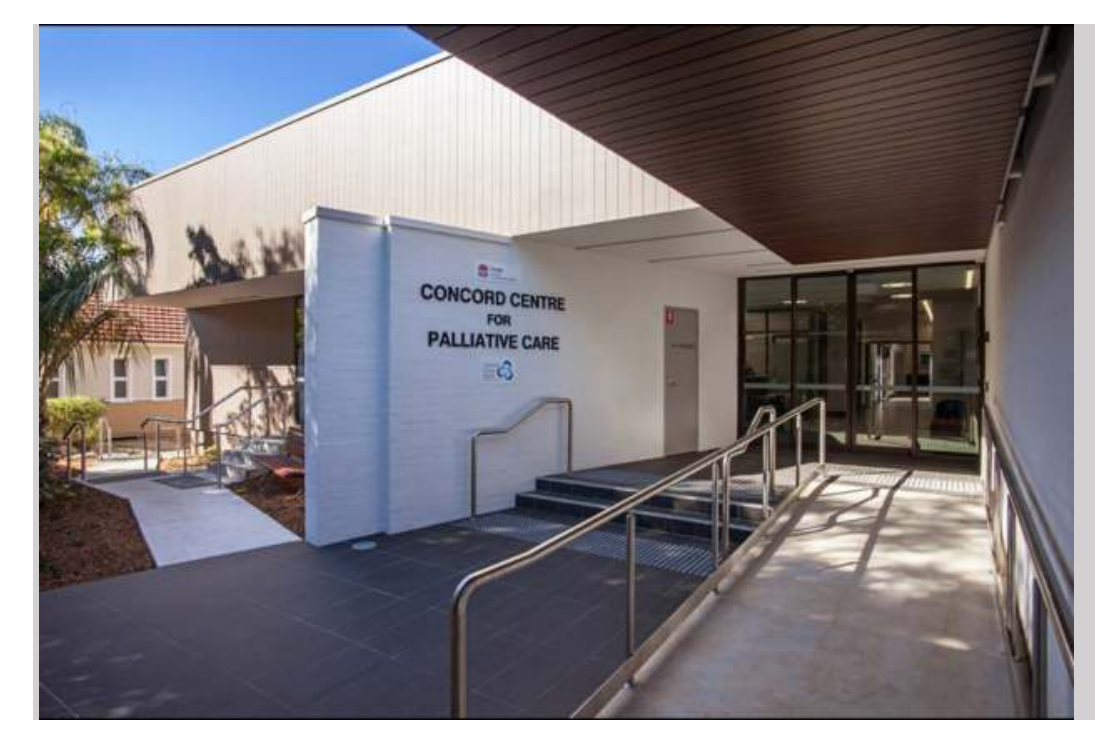

\section{REFERENCES}

Thekkumpurath, P., Venkateswaran, C., Kumar, M., \& Bennet, M. I. (2008). Screening for psychological distress in palliative care: a systematic review. Journal of Pain and Symptom Management, 36(5), 520-528. https://doi.org/10.1016/i.painsymman.2007.11.010

The National Comprehensive Cancer Network® (NCCN®). (2017). NCCN Distress Thermometer and Problem List. Version 1, 2017. Retrieved 18 February 2017. Available from https://www.nccn.org/about/permissions/thermometer.aspx

Ma, X., Zhang, J., Zhong. W., Shu, C., Wang F., Wen, J., ... Liu, L. (2014). The diagnostic role of a short screening tool--the distress thermometer: a metaanalysis. Supportive Care in Cancer: Official Journal of the Multinational Association of Supportive Care in Cancer, 22(7), 1741-1755. https://doi.org/10.1007/ analysis. Supportive Care in Cancer: Official Journal of the Multinational Association of Supportive Care in Cancer, 22(7), 1741-1755. hitps://doi.org/10.1007/
s00520-014-2143-1

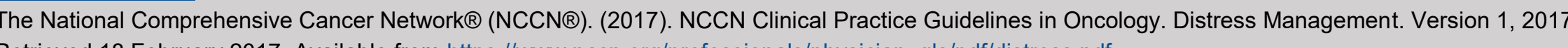
Retrieved 18 February 2017. Available from https://www.nccn.org/professionals/physician gls/pdf/distress.pdf 